\title{
Estimativa quantitativa da resposta à clortetraciclina em um caso grave de disenteria por Balantidium coli
}

\author{
R. G. P. Rees (")
}

A. J. Shelley ("t)

\begin{abstract}
Resumo
Feita uma tentativa de determinar a eficácia terapêtica da clortetraciclina em um caso grave de disenteria por Balantidium. Foram feitas várias esímativas da população de trofozoitos de Balan. tidium, a partir de fezes de 24 horas, antes e durante o tratamento de 4 dias com a droga. Houve uma redução marcante no número de parasitas eliminados durante o tratamento, associada a uma melhora clínica significativa nas condiçōes da paciente.
\end{abstract}

\section{INTRODUÇÃo}

Infecções humanas por $B$. coli são relativamente raras e são geralmente encontradas em regiões tropicais do mundo. No Brasil, tais casos são relatados esporadicamente (Ximenes Neto et al., 1971), embora tenha sido re. gistrada baixa prevalência de portadores deste parasita em várias regiōes. Vallada (1967) relatou $0,015 \%$ de fezes positivas para $B$. coli no interior do Estado de S. Paulo, de um total de 78.985 casos, enquanto que, em 1971, Araújo encontrou prevalência variando de 0 a $8,63 \%$ de um total de 3.832 exames feitos em 4 municipalidades do Estado de Goiás. Em Recife, 29 portadores deste parasita $(4,79 \%)$ foram encontrados em um levantamento entre 605 criadores de porcos (Teixeira, 1974) .

Ręlatamos um caso de disenteria por Balantidium em uma mulher índia na qual foi feita uma tentativa para verificar a resposta ao tratamento, através de estimativa quantitativa do número de trofozoítos de $B$. coli nas fezes.

\section{RELATO DO CASO E RESUltados}

Em dezembro de 1975, em uma missão no rio Toototobi (afluente do Demini, no norte do Estedo do Amazonas, Brasil), uma mulher ín- dia, Yanomama, de 35 a 40 anos de idade, apresentou-se com uma história de disenteria por vários meses, dores abdominais fracas, anorexia e perda de peso (Fig. 1). No exame ela se mostrou severamente emaciada, $(26,5 \mathrm{~kg})$ com uma temperatura de $37,2^{\circ} \mathrm{C}$, pulso de 126 / min., e uma sensivel hepatomegalia a $2 \mathrm{~cm}$ abaixo do rebordo costal. As fezes eram diarréicas com traços de sangue e muco. $\mathrm{O}$ exame

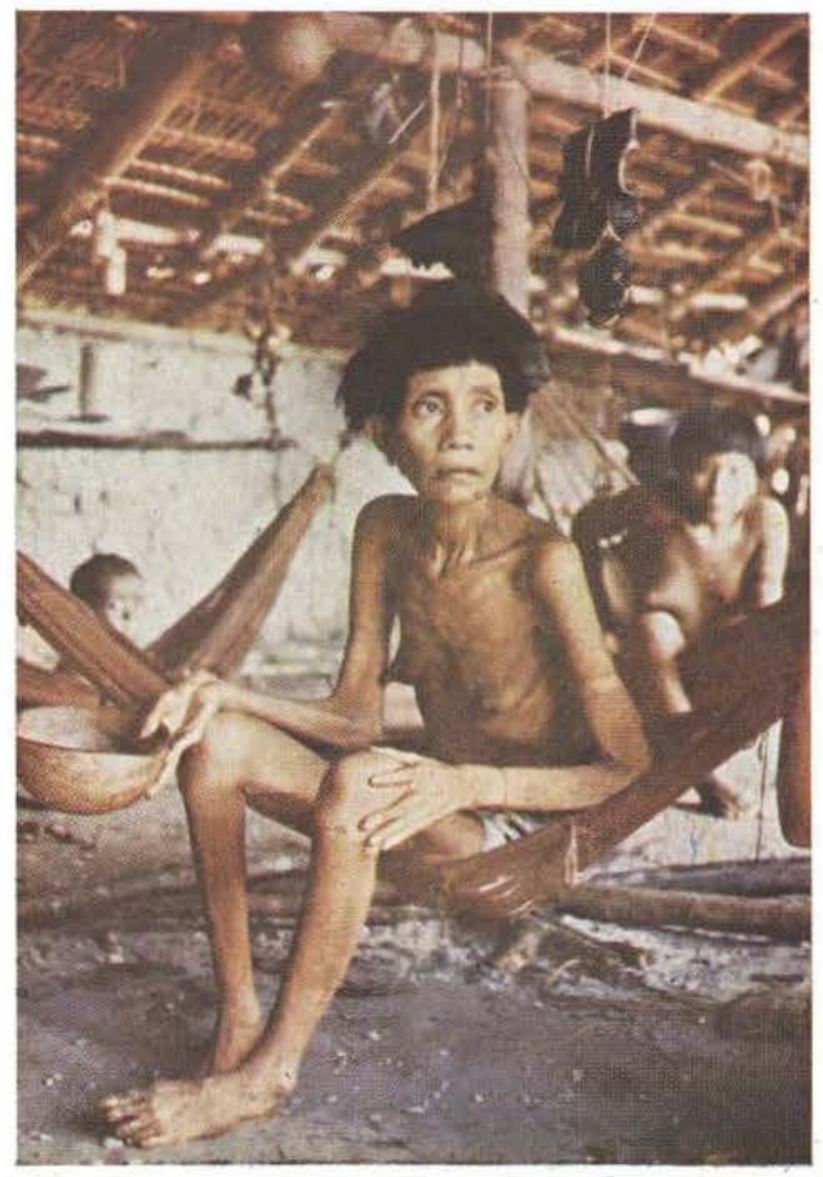

Fig. 1 - Mulher índia emaciada com disenteria por Balantidium.

(•) - Departamento de Nutrição, Universidade de Brasília, Brasília - DF.

(*) - Laboratório de Parasitologia, Instituto de Ciências Biológicas, Universidade de Brasília, Brasília - DF. 
microscópico mostrou grande número de trofozoítos de Balantidium coli. Ovos de Ascaris, Trichuris e Ancilostomidae estavam também presentes (Fig. 2) .

Três coletas de fezes de 24 horas foram feitas durante 4 dias consecutivos. O tratamento foi iniciado no $1 .^{\circ}$ dia com uma dosagem oral de $250 \mathrm{mg}$ de clortetraciclina a cada 6 horas (eram disponíveis apenas pequenas quantidades da droga). Após o $3 .^{\circ}$ dia a ciose de ciortetraciclina foi aumentada para $2 \mathrm{~g}$ ciárias.

A coleta anterior e as duas coletas posteriores ao tratamento foram preservadas separadamente em solução de mertiolate - iodo - formol (MIF), até a chegada ao laboratório, aproximadamente 4 semanas mais tarde. Cada coleta foi então homogeneizada por agitações repetidas na solução preservadora e, então, filtrada através de gaze de algodão para remover as fibras e partículas maiores. Usando mais solução de MIF, os resíduos separados foram lavados e filtrados várias vezes para remover os trofozoítos restantes. Os volumes totais dos extratos fecais foram então observados, e usando pipeta Sahli $\left(20 \mathrm{~mm}^{3}\right)$ foram tomadas 10 aliquotas de cada um e preparados esfregaços diretos sob lamínulas de $32 \times 24 \mathrm{~mm}$. Os trofozóitos foram contados na área total da lamínula com um aumento de $125 \mathrm{X}$. Por meio destas contagens as produções diárias de parasitos foram computadas.

Em resposta ao tratamento, as evacuações tornaram-se consistentes e menos freqüentes apesar de persistirem pequenas quantidades de sangue e muco. As condições gerais da paciente começaram a melhorar. A hepatomegalia, contudo, ainda estava presente no $4 .^{\circ}$ dia de tratamento, mas sem sensibilidade. $O$ efeicio do tratamento sobre o número de parasitas contados nas fezes é mostrado na tabela 1 .

\section{DISCUSSÃo}

Os resultados indicam claramente considerável redução no número de parasitos em resposta à clortetraciclina. Esta redução é paralela à melhoria clínica da paciente.

Trofozoítos de $B$. coli podem não estar distribuidos aleatoriamente nas fezes e a técnica de tomar alíquotas da suspensão fecal total de
24 horas evita possíveis dúvidas associadas ès contagens feitas em esfregaços de amostras fecais pré-selecionadas. O último método foi usado em um recente trabalho relatando estimativas de Giardia nas fezes (Danciger \& Lopez, 1975). Para este parasita, contudo, a distribuição fecal pode não ser um problema, uma vez que a Giardia habita o intestino delgado, permitindo adequada mistura dos protozoários com as fezes antes da excreção.

As tetraciclinas permanecem como o tratamento padrão para balantidíase (Knight et al, 1973), apesar de que em uma recente publicação da Venezuela (Laverde \& Bonilla, 1975) o metronidazole eliminou os $B$. coli de todos os 20 casos após o $4 .^{\circ}$ dia de tratamento. Deve ser notado contudo que estes pacientes aparentemente não estavam sofrendo de disenteria.

A origem da infecção em estudo não era óbvia. Vinte e um dos 30 índios da aldeia incluindo a familia da paciente - foram examinados por esfregaço direto das fezes para infecção por $B$. coli e todos foram negativos. Todos mostraram infecção helmíntica mista,

TABELA 1 - Efeito da clortetraciclina na eliminação de trofozoítos de B. coli.

\begin{tabular}{|c|c|c|c|c|}
\hline $\begin{array}{c}\text { Coleta } \\
\text { fecal } \\
(24 \text { hs })\end{array}$ & $\begin{array}{l}\text { Dose } \\
\text { diária de } \\
\text { clorte- } \\
\text { traciclina } \\
(9)\end{array}$ & $\begin{array}{c}\begin{array}{c}\text { Volume } \\
\text { da }\end{array} \\
\text { suspensāo } \\
\text { fecal } \\
\text { (ml) }\end{array}$ & $\begin{array}{l}\text { Contagem } \\
\text { esfregaços } \\
\text { (média de } 10 \\
\text { aliquotas de } \\
\text { de } 20 \mathrm{~mm} 3 \\
\text { com desvio } \\
\text { padrăo) }\end{array}$ & $\begin{array}{l}\text { Total de } \\
\text { trofozoitos } \\
\text { eliminados } \\
\text { diariamente } \\
\left(x 1^{6}\right)\end{array}$ \\
\hline
\end{tabular}

Pré-

trata-

mento:

$\begin{array}{llll}\text { várias } & 0 & 2.100 & 107 \pm 11\end{array}$

fezes

diarréicas

Pós-tra-

tamento

3. dia

(fezes

formadas)

Pós-tra-

tamento

$4 .^{\circ}$ dia

2

1.067

$4 \pm 2$

0,21

(fezes

tormadas) 


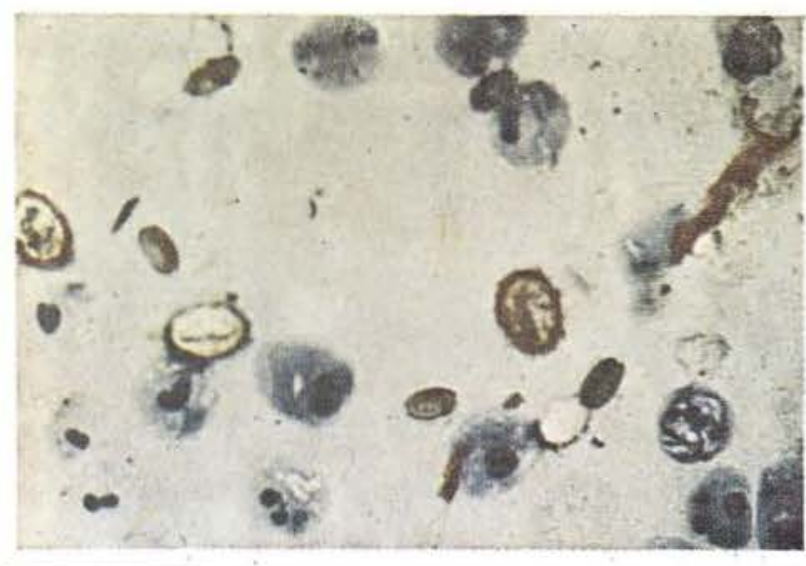

Fig. 2 - Esfregaço fecal direto corado com hematoxilina férrica mostrando trofozoitos de Balantidium coli e ovos de Ascaris lumbricoides e Trichuris trichiura.

com uma alta prevalência de trichuríases. A infecçăo por Trichuris em nossa paciente pode tê-la predisposto à disenteria por Balantidium. Uma relação funcional entre estas duas infecções foi sugerida por pesquisadores venezuelanos (Laverde \& Bonilla, 1975). Finalmente. nossa paciente não tinha história de contato com porcos domésticos, embora os índios Yanomama comam regularmente porcos selvagens e macacos, conhecidos reservatórios de B. coli.

Não foi possível seguir o tratamento e o progresso desta paciente, pois, após o $4 .^{\circ}$ dia de terapia os autores deixaram a região.

Relatamos este caso principalmente como uma tentativa de quantificar o progresso de uma infecção intestinal tal como a balantidiose, fornecendo assim um método direto de ava. liação do tratamento.

\section{AGRADECIMENTOS}

Gostariamos de agradecer ao Sr. Bruce Hartman da Missão Toototobi por sua inestimável assistência; ao Prof. W. Lobato Paraense pelo uso das facilidades de seu laboratório e ao Prof. P.H. Marsden por ler o manuscrito.
Ao Conselho Nacional de Desenvolvimen to Científico e Tecnológico que providenciou assistência financeira.

A Dra. Loreny Giugliano que traduziu o trabalho para o português

\section{SUMMARY}

The therapeutic efficiency of chlortetracyclines for the treatment of Balantidial dysentery was tested in a Yanomama indian. Parasite counts were made on 24 hour samples of the patient's faeces. before treatment and on the third and fourth day of treatment. A marked reduction in parasite counts was seen during treatment associated with an improvement in the patient's condition.

\section{BIBLIOGRAFIA CITADA}

AraúJo, O.A.

1971 - Parasitoses intestinais em quatro municípios goianos. Rev. Goiana Med. $17: 49-55$.

DANCIGER, M. \& LOPEZ, M.

1975 - Numbers of Giardia in the feces of infected children. Am. J. Trop. Med. Hyg. $24: 237-242$.

Knight, R.; Schultz, M.G.; Hoskins, D.W. \& Marsden, P.D.

1973 - Intestinal parasites. Gut 14:145-168.

LAVERde, A.G. \& BONILlA, L.

1975 - Clinical trials with metronidazole in human balantidiasis. Am. J. Trop. Med. Hyg. 24 : 781-783.

TEIXEIRA, H.

1974 - fndice de infecção balantıdiana entre criadores de suínos em arrebaldes do Recife, Brasil. Universidade Federal de Pernambuco, Editora Universitária, Recife.

Vallada, E.P.

1967 - Balantidium coli em Itapetininga. O hospital $72: 821$.

Ximenes Neto, M.; Costa Sobrinho, V.M.; Ferreira, D. \& Avelino, M.G.

1971 - Perfuração colônica por Balantidium coli. Rev. Goiana Med. $17: 65-73$. 